\title{
Residency Training: Progressive gait difficulty and incontinence in a 40-year-old man with HIV
}

Andrew Silverman, BS, * Tess O’Meara, BA, * Leah Le, BS, MPH, Kevin Robertson, PhD, and Serena Spudich, MD

Neurology ${ }^{\circledR}$ 2018;91:1065-1070. doi:10.1212/WNL.0000000000006619
Correspondence

A. Silverman

andrew.silverman@yale.edu

\section{Section 1}

A 40-year-old South African man presented with progressive difficulty walking, bilateral leg weakness, and balance problems. He described vague cognitive symptoms and new-onset urinary incontinence. Notwithstanding a $2008 \mathrm{HIV}$ diagnosis (infection date unknown), due to social issues he did not obtain medical care. There was no medical history of opportunistic infections (OIs) or other problems associated with HIV. Three months before presentation, however, he had stopped working as a home care assistant due to unsteady gait. In addition, he described a recent 30-pound weight loss. He denied headaches or neck pain. There was no relevant family history, and he took no medication.

The patient had normal vital signs and was well-appearing, alert, and oriented to person, date, and setting. On initial examination, he was considered to have normal mental status. However, on further evaluation, his speech was noted to be quiet and slow, and there was a question between examiners whether his flattened affect was culturally determined. When asked to name words beginning with the letter $\mathrm{F}$, he was able to name 6 in 1 minute (normal $>14$ ). His upper extremity strength was $5 / 5$ bilaterally, and $4 / 5$ strength was noted in both hip flexors. $\mathrm{He}$ displayed small, slow, and clumsy finger and foot taps, and snout and jaw jerk reflexes were present. Furthermore, he was incontinent of urine multiple times throughout the examination. Hoffmann sign and hyperreflexia were not present. There was no neck stiffness, papilledema, or skin findings. Visual field and cranial nerve testing was normal, and the remainder of the neurologic and general examinations was unremarkable.

\section{Question for consideration:}

1. What is your differential diagnosis at this stage?

GO TO SECTION 2

\footnotetext{
*These authors contributed equally to this report.
}

Department of Neurology (A.S., T.O., L.L., S.S.) and Center for Neuroepidemiology and Clinical Neurological Research (S.S.), Yale University School of Medicine, Yale University, New Haven, CT; and Department of Neurology (K.R.), University of North Carolina School of Medicine, Chapel Hill.

Go to Neurology.org/N for full disclosures. Funding information and disclosures deemed relevant by the authors, if any, are provided at the end of the article. 


\section{Section 2}

The onset of symptoms over several months implicates various possible etiologies including neoplastic, metabolic, inflammatory, and neurodegenerative processes. In considering a supratentorial vs spinal process, the differential diagnosis remains broad: inflammatory and neurodegenerative diseases of the CNS (e.g., myelitis related to autoimmune or paraneoplastic processes), metabolic disorders (e.g., vitamin $\mathrm{B}_{12}$ or folate deficiency), and infectious diseases (e.g., human T-lymphotropic virus, syphilis, Lyme). The combination of urinary incontinence and gait instability could be attributed to a spinal cord defect; however, the presence of primitive reflexes (snout and jaw jerk), in combination with bradyphrenia, suggests that diffuse or frontally predominant subcortical dysfunction must also be involved. Vacuolar myelopathy must be considered in a patient with advanced HIV and gait disturbance, though the lack of hyperreflexia and sensory loss renders localization to the posterolateral spinal columns unlikely. The absence of lateralizing signs points away from focal lesions such as CNS lymphoma or progressive multifocal leukoencephalopathy (PML), though if extensive and bilateral, these could produce a consistent clinical picture.

In this case, the constellation of urinary incontinence, cognitive impairment, and gait instability strongly implies a subcortical frontal lobe condition, with or without additional cord involvement. While normal pressure hydrocephalus (NPH) is on the differential, conditions more common in a potentially immunocompromised patient should be considered. Given the setting of treatment-naive HIV infection, PML and cerebral toxoplasmosis should be ruled out. Causes of more generalized encephalopathy associated with immunosuppression and infection, including cryptococcal meningitis and HIV-associated dementia, should also be considered.

\section{Question for consideration:}

1. What additional diagnostic tests would you consider? 


\section{Section 3}

Given the reported HIV diagnosis, a blood CD4 count and quantitative plasma HIV RNA level in addition to an infectious disease panel should be ordered. To further localize the pathology, MRI examinations of the spinal cord and brain along with blood and CSF examinations should be performed.

Laboratory testing revealed a CD4 count of 31 cells $/ \mu \mathrm{L}$ (normal 500-1,500) and plasma HIV viral load 1.7 million copies $/ \mathrm{mL}$. The patient's complete blood count revealed leukopenia, thrombocytopenia, and mild anemia (white blood cells 2,100 cells $/ \mu \mathrm{L}$, hemoglobin $12.5 \mathrm{~g} / \mathrm{dL}$, hematocrit $38.9 \%$, platelets 100,000 cells $/ \mu \mathrm{L}$ ). Serum chemistries, liver profile, lipid panel, vitamin $B_{12}$, and folate levels were normal. Plasma infectious and sexually transmitted disease screening tests were negative with the exception of positive cytomegalovirus (CMV) immunoglobulin G, weakly positive CMV
DNA PCR $(<137 \mathrm{IU} / \mathrm{mL})$, and reactive hepatitis A and hepatitis B total core antibodies. A lumbar puncture yielded CSF with glucose $39 \mathrm{mg} / \mathrm{dL}$, protein $134 \mathrm{mg} / \mathrm{dL}$, and 9 white blood cells $\mu \mathrm{L}$ (93\% lymphocytes). The CSF microbiology panel was negative except for CSF HIV RNA count $>10$ million copies $/ \mathrm{mL}$.

On brain MRI, prominence of the ventricles and sulci was visualized with diffusely symmetric, periventricular T2 hyperintensity on fluid-attenuation inversion recovery (FLAIR) signal within the supratentorial white matter, extending into the corona radiata (figure 1). The spine MRI was normal, with no abnormal enhancement on postcontrast imaging.

\section{Questions for consideration:}

1. What is the diagnosis?

2. Are there any additional diagnostic evaluations you might perform?

Figure 1 Fluid-attenuated inversion recovery MRI

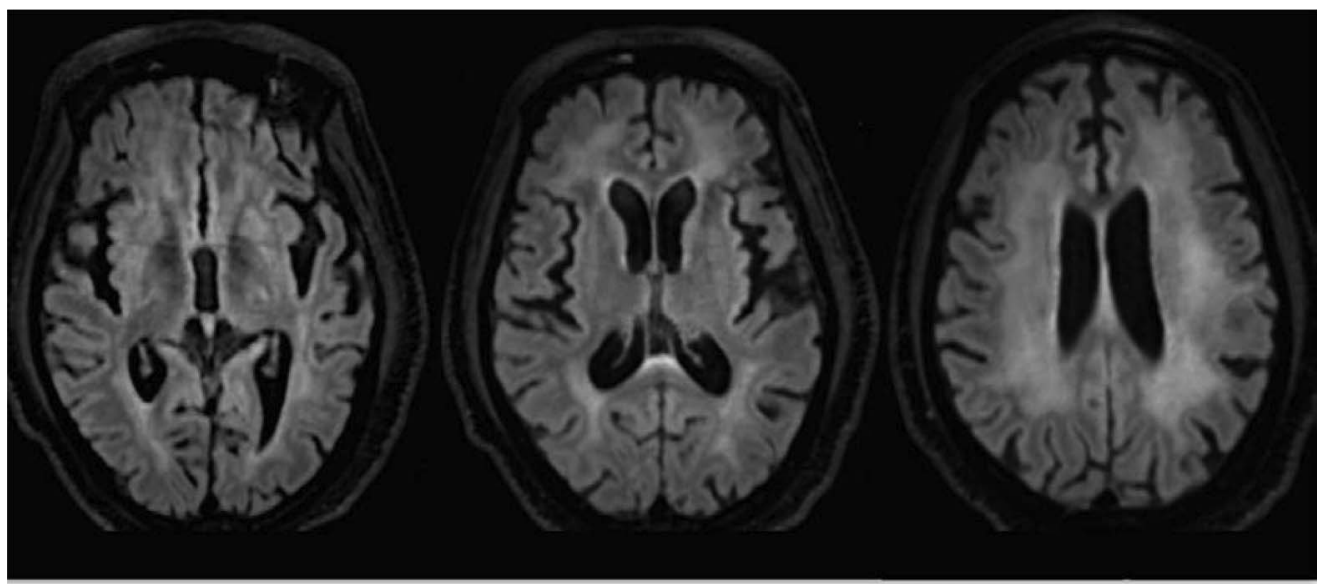

GO TO SECTION 4 


\section{Section 4}

The patient's clinical picture and laboratory findings point strongly towards a diagnosis of HIV-associated dementia (HAD). Laboratory tests and neuroimaging effectively ruled out other metabolic and infectious etiologies, including toxoplasmosis and CNS lymphoma, which would appear as multiple or isolated ring-enhancing lesions, respectively, with positive CSF findings. Instead, the patient's diffuse subcortical T2 hyperintensity on FLAIR MRI is more characteristic of HIV encephalitis. In addition, while the patient's clinical picture may be similar to one of NPH, NPH is a disease of the elderly ( $>65)$. This patient instead represents a case of advanced AIDS and HAD.
To further characterize the patient's disease, comprehensive neuropsychological testing was performed. Neuropsychological evaluations help determine the degree of neurocognitive impairment and monitor its resolution or persistence on therapy. ${ }^{1}$ The raw neuropsychological scores were standardized using data from HIV-uninfected, age- and education-matched controls. Our patient's sum neuropsychological score was roughly $3 \mathrm{SD}$ below the neurotypical mean. In particular, major domains of impairment included gross and fine motor skills, processing speed, attention, executive function, as well as verbal learning (figure 2).

\section{Question for consideration:}

1. What would you do now in the management of this patient?

Figure 2 Longitudinal neuropsychological testing

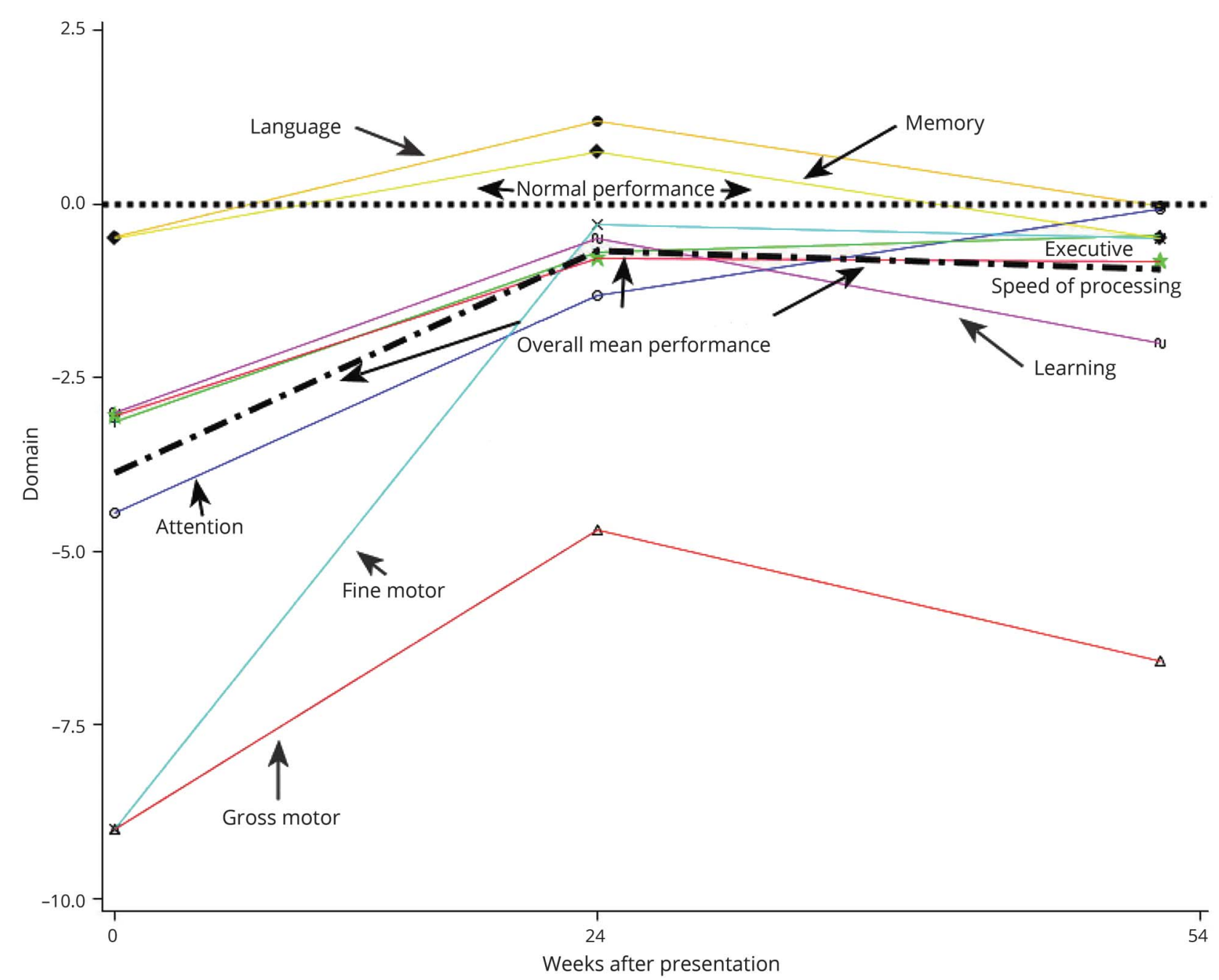

Neurocognitive improvement in performance in HIV-associated dementia (HAD) with treatment after presentation. Gross and fine motor functioning were the most affected areas at baseline, a classic presentation underlying the damage to myelinated tracts in white matter, as commonly seen in HAD. Other domains, listed from most to least impaired, were attention, speed of processing, executive function, and learning. These domains are also affected by demyelination/damage in white matter, often periventricular, and by tracts leading from there to prefrontal and frontal cortex (executive, learning). Relatively preserved domains that remained normal throughout were language skills and verbal memory. 


\section{Section 5}

Under close inpatient monitoring, combination antiretroviral therapy (cART) was initiated in the form of Triumeq, a single daily tablet comprising abacavir $(600 \mathrm{mg})$, dolutegravir $(50$ $\mathrm{mg}$ ), and lamivudine $(300 \mathrm{mg})$. The patient received prophylactic azithromycin (1200 mg once/wk) and sulfamethoxazole/trimethoprim $(800 / 160 \mathrm{mg} \mathrm{qd})$ to prevent OIs.

Two weeks following initiation of treatment, measures of viral load and lymphocyte counts dramatically improved in proportion with the patient's clinical examination. At 24 weeks after CART initiation, repeat neuropsychological testing demonstrated substantial improvement across motor and verbal domains with pronounced improvement in gait.

\section{Discussion}

Prior to widespread access to cART, neurologic manifestations appeared in at least 70\% of HIV-infected individuals. ${ }^{2}$ Meningitis, meningoencephalitis, and peripheral neuropathy are manifestations of primary HIV infection. During later stages of disease, both OIs and HAD, caused by HIV itself, can develop. ${ }^{3}$ Among the OIs, cerebral toxoplasmosis, PML, and primary CNS lymphoma often present with focal hemispheric dysfunction (i.e., hemiparesis, aphasia, apraxia, or hemisensory impairment). ${ }^{4}$ Causes of nonfocal CNS conditions include CMV encephalitis, cryptococcal meningitis, metabolic and toxic encephalopathies, and HAD.

HAD is characterized by a constellation of cognitive, motor, and behavioral symptoms. ${ }^{5}$ Its diagnosis is based on clinical determinations and the exclusion of other diseases by CSF analysis and neuroimaging. In contrast to the acute or subacute onset of most OIs, HAD tends to be slowly progressive with insidious changes in the neurologic examination. Normalized neuropsychological testing is utilized to characterize the nature and extent of any cognitive difficulties. ${ }^{6}$

The clinical presentation of HAD is varied and progressive. Early symptoms include memory deficits or slowed mental function, whereas motor symptoms develop later, including decline in manual dexterity, dysdiadochokinesia, and hyperreflexia. HAD exists on a spectrum of HIV-associated neurocognitive disorders that includes asymptomatic neurocognitive impairment and mild neurocognitive disorder. These conditions are differentiated by severity of neurologic impairment as delineated by the Frascati criteria, with HAD representing the highest degree of functional impairment. ${ }^{5}$ Predominant motor dysfunction seen in HAD is useful in distinguishing this frontal subcortical dementia from cortical dementias such as Alzheimer disease, which is characterized by early word-finding difficulties in addition to cortical signs like loss of spatial awareness. In addition, the presence of jaw jerk and snout reflexes, as seen in our patient, in conjunction with periventricular hyperintensity on MRI indicate a frontal release syndrome that is characteristic of HAD. In fact, primitive reflexes were found to be independent predictors of HIV-1 serostatus, especially for those with cognitive dysfunction. ${ }^{7}$

Today, HAD is almost exclusively seen in patients without access to cART or those undergoing treatment but with insufficient viral suppression; for example, because of poor adherence or drug resistance. ${ }^{8}$ Most patients with HAD placed on cART experience improvement of their symptoms. ${ }^{9}$ Notably, although $\mathrm{HAD}$ is uncommon in treated patients, subtler forms of HIV-associated neurocognitive disorders have a persistently high prevalence in individuals on cART with intact immune systems.

In the era of effective cART, clinical familiarity with HAD has declined with its incidence. In reviewing our patient's health record, not one provider addressed the possibility that the patient's primary diagnosis was related solely to HIV infection. It was our motivation to report this case as a reminder of what became well-established in the 1990s, at the peak of the AIDS epidemic, particularly because of the reversible nature of HAD upon initiation of cART. Our patient was an immigrant not connected to the US health care system following an HIV diagnosis. Now, after years of persistent infection, he presented with a canonical body of $\mathrm{HAD}$ signs and symptoms that were characterized decades ago. ${ }^{5}$

\section{Author contributions}

A. Silverman: case concept and design, primary authorship. T. O'Meara: case concept and design, primary authorship. L. Le: provided patient background information. K. Robertson: provided neuropsychological expertise. S. Spudich: case concept, provided critical revision of manuscript for intellectual content.

\section{Study funding}

No targeted funding reported.

\section{Disclosure}

A. Silverman, T. O'Meara, L. Le, and K. Robertson report no disclosures relevant to the manuscript. S. Spudich reports that ViiV, Healthcare, Inc. contributes study medications to a clinical trial codirected by Dr. Spudich through the AIDS Clinical Trials Group. Go to Neurology.org/N for full disclosures.

\section{References}

1. Sanmarti M, Ibáñez L, Huertas S, et al. HIV-associated neurocognitive disorders. J Mol Psychiatry 2014;2:2.

2. Simpson DM, Tagliati M. Neurologic manifestations of HIV infection. Ann Intern Med 1994;121:769-785.

3. Price RW, Brew B. Management of the neurologic complications of HIV infection and AIDS. Infect Dis Clin North Am 1988;2:359-372.

4. Price RW. Neurological complications of HIV infection. Lancet 1996;348:445-452.

5. Antinori A, Arendt G, Becker JT, et al. Updated research nosology for HIV-associated neurocognitive disorders. Neurology 2007;69:1789-1799. 
6. Pozniak A, Rackstraw S, Deayton J, et al. HIV-associated neurocognitive disease: case studies and suggestions for diagnosis and management in different patient subgroups. Antivir Ther 2014;19:1-13.

7. Tremont-Lukats IW, Serbanescu R, Teixeira GM, et al. Multivariate analysis of primitive reflexes in patients with human immunodeficiency virus type- 1 infection and neurocognitive dysfunction. Ital J Neurol Sci 1999;20:17-22.
8. McArthur JC, Hoover DR, Bacellar H, et al. Dementia in AIDS patients: incidence and risk factors: multicenter AIDS Cohort Study. Neurology 1993;43: 2245-2252.

9. Dore GJ, McDonald A, Li Y, et al. Marked improvement in survival following AIDS dementia complex in the era of highly active antiretroviral therapy. AIDS 2003;17: $1539-1545$.

\section{Subspecialty Alerts by E-mail!}

Customize your online journal experience by signing up for e-mail alerts related to your subspecialty or area of interest. Access this free service by clicking on the "My Alerts" link on the home page. An extensive list of subspecialties, methods, and study design choices will be available for you to choose from-allowing you priority alerts to cutting-edge research in your field!

\section{Share Your Artistic Expressions in Neurology 'Visions'}

AAN members are urged to submit medically or scientifically related artistic images, such as photographs, photomicrographs,

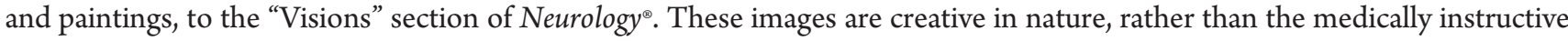
images published in the NeuroImages section. The image or series of up to six images may be black and white or color and must fit into one published journal page. Accompanying description should be 100 words or less; the title should be a maximum of 96 characters including spaces and punctuation.

Please access the Author Center at NPub.org/authors for full submission information.

\section{Sign Up for the AAN's Axon Registry}

The AAN encourages its US members to show their interest in participating in the Axon Registry ${ }^{\circledR}$ by signing up today.

Use the Axon Registry to:

- Simplify reporting requirements under MACRA's Quality Payment Program and avoid penalties while reducing your administrative burden

- Meet your MOC Part IV requirements and waive up to eight credits of Part II Self-Assessment

- Choose from 22 AAN neurology-specific quality measures that fit your practice

- Use data to understand your practice and identify where improvements can be made to patient care

- Manage your patients at a population level; look at a specific group of patients based on conditions, risk factors, demographics or outcome

- Demonstrate your value to payers when negotiating reimbursement

- Enjoy multi-year, fee-free access when you sign the agreements and integrate your EHR with the registry

Learn more at AAN.com/view/Axon and send your questions to registry@aan.com. 


\section{Neurology}

\section{Residency Training: Progressive gait difficulty and incontinence in a 40-year-old man with HIV}

Andrew Silverman, Tess O'Meara, Leah Le, et al.

Neurology 2018;91;1065-1070

DOI 10.1212/WNL.0000000000006619

This information is current as of December 3, 2018

\section{Updated Information \&} Services

References

Subspecialty Collections

Permissions \& Licensing

\section{Reprints}

including high resolution figures, can be found at: http://n.neurology.org/content/91/23/1065.full

This article cites 9 articles, 2 of which you can access for free at: http://n.neurology.org/content/91/23/1065.full\#ref-list-1

This article, along with others on similar topics, appears in the following collection(s):

Assessment of cognitive disorders/dementia

http://n.neurology.org/cgi/collection/assessment_of_cognitive_disorder S_dementia

\section{HIV}

http://n.neurology.org/cgi/collection/hiv

HIV dementia

http://n.neurology.org/cgi/collection/hiv_dementia

Neuropsychological assessment

http://n.neurology.org/cgi/collection/neuropsychological_assessment

Information about reproducing this article in parts (figures,tables) or in its entirety can be found online at:

http://www.neurology.org/about/about_the_journal\#permissions

Information about ordering reprints can be found online:

http://n.neurology.org/subscribers/advertise

Neurology ${ }^{\circledR}$ is the official journal of the American Academy of Neurology. Published continuously since 1951, it is now a weekly with 48 issues per year. Copyright (C) 2018 American Academy of Neurology. All rights reserved. Print ISSN: 0028-3878. Online ISSN: 1526-632X.

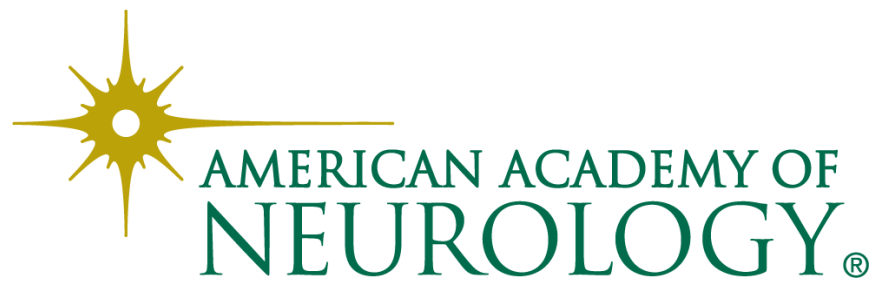

